\title{
LONDON TELEPHONE AREAS
}

\section{CENTRE}

Dial House

151 Shaftesbury Avenue

London WC2H 8BA

Telephone: 014348060

Telex: 21188

\section{CITY}

Riverside House

2A Southwark Bridge Road

London SE1 9BA

Telephone: 019218888

Telex: 21144

\section{EAST}

Telephone House

4-20 Woodgrange Road

Forest Gate

London E7 0BA

Telephone: 015348060

Telex: 21153

\section{NORTH}

Telephone House

Crouch End Hill

London N8 8BA

Telephone: 013408060

Telex: 21233

\section{NORTH CENTRAL}

Fleet Building

40 Shoe Lane

London EC4A 3DD

Telephone: 018291234

Telex: 261851

\author{
NORTH WEST \\ Telephone House \\ 1-15 Shootup Hill \\ London NW2 3BA \\ Telephone: 012065656 \\ Telex: 21233

\section{SOUTH} \\ Impact House \\ 2 Edridge Road \\ Croydon CR9 1BT \\ Telephone: 017607711 \\ Telex: 27521 \\ SOUTH CENTRAL \\ Erlang House \\ St Georges Circus \\ London SE1 8BA \\ Telephone: 012614343 \\ Telex: 265220 \\ SOUTH EAST \\ Telephone House \\ 24 Westmoreland Place \\ Masons Hill \\ Bromley BR1 1BA \\ Telephone: 012902345 \\ Telex: 21147

\section{SOUTH WEST} \\ Telephone House \\ 21-33 Worple Road \\ London SW19 4BA \\ Telephone: 018791234 \\ Telex: 21244

\section{WEST} \\ Westel House \\ 32-38 Uxbridge Road \\ London W5 2BA \\ Telephone: 015798321 \\ Telex: 21109
}

